\title{
Integrated modeling of EM response functions from Peninsular India and Bay of Bengal
}

\author{
Baldev R. Arora and P. B. V. Subba Rao
}

Indian Institute of Geomagnetism, Colaba, Mumbai 400 005, India

(Received March 13, 2001; Revised September 19, 2001; Accepted November 12, 2001)

\begin{abstract}
Existing sets of magnetovariational data from the large numbers of sites distributed across the peninsular India and those in the Bay of Bengal are reanalysed to obtain inter-site vertical and horizontal field transfer functions. Maps of induction arrows relocate the earlier reported conductive zones beneath the Palk-Strait and a regional scale anomaly in the offshore region, immediately southwest of the southern tip of Indian Peninsula, named South India Offshore Conductivity Anomaly (SIOCA). Period dependence of the induction arrows suggests that with increasing period SIOCA tends to control the induction pattern over the entire peninsula. Presentation of the horizontal transfer functions in the form of ellipses of anomalous currents helps to characterize the period and spatial behaviour of horizontal fields at seafloor sites. Integrated thin sheet modeling of the on-land and seafloor induction features suggest that the greater part of the anomalous behaviour of the horizontal fields at seafloor sites can be attributed to the shielding effects due to seawater. The weak anisotropic behaviour of the horizontal fields at selected sites can be explained in terms of the concentration of the induced currents in the sediment filled troughs on either side of the $85^{\circ}$ E Ridge. Several lines of geophysical evidence favour the hypothesis that SIOCA, low velocity zone, low magnetization anomaly, all centered near the southern tip of the India, are the relics of the interaction of Marion Plume outburst with Indian lithosphere.
\end{abstract}

\section{Introduction}

The electrical conductivity distribution bordering the southern tip of the Indian Peninsula has been shown earlier to be highly anomalous and complex (for review see Arora, 1990 and references therein). First such deductions were based on the anomalous character of transient geomagnetic variations at permanent geomagnetic observatories; namely, Trivandrum, Kodaikanal and Annamalainagar. The anomalies that prevail both in vertical (Singh et al., 1977) and horizontal field components (Singh et al., 1982; Nityananda et al., 1977) and persist over wide range of periods (from SSc to Storm-time) were qualitatively interpreted to indicate channeling of induced currents through a subsurface conductor between India and Sri Lanka (Rajaram et al., 1979). The subsequent large-scale regional magnetometer array not only corroborated such speculations but also provided evidence on additional conductors (Thakur et al., 1986). The quantification of induction response from the array data paved the way for a number of numerical modeling exercises to locate and define the character of conductive structures, the concentration of currents through which accounts for the observed induction anomalies. The 3-D model, devised by Ramaswamy et al. (1985) supported the hypothesis of a subsurface conductor along the Palk-Strait between India and Sri Lanka. However, later updated models by Mareschal et al. (1987) and Agarwal and Weaver (1989), both using a thin sheet formulation, showed that a combination of crustal con-

Copy right (C) The Society of Geomagnetism and Earth, Planetary and Space Sciences (SGEPSS); The Seismological Society of Japan; The Volcanological Society of Japan; The Geodetic Society of Japan; The Japanese Society for Planetary Sciences. ductors located in the Palk-Strait and underneath Comorin Ridge with extension up to the west coast provide better fit to the anomalous variations observed in the whole of the peninsular region.

Following this success of on-land magnetovariational studies in mapping large-scale conductive structures, coupled with parallel progress in the design and development of ocean bottom magnetometers (OBM), numbers of campaigns have been carried out in adjoining Bay of Bengal. Much of these seafloor arrays, using 4-5 OBMs at a time, have focused across the $85^{\circ} \mathrm{E}$ and Ninetyeast Ridges. Both these ridges are demonstrated to be traces of hotspots and constitute the most prominent tectonic elements of the Bay of Bengal (Curray et al., 1982). Although analysis and interpretation separately of the on-land (references cited above) and seafloor data (Joseph et al., 1995, 2000; Subba Rao et $a l ., 2000)$ has been carried out quite extensively, their combined interpretation has still not been attempted. The present paper is an attempt towards the integration and joint interpretation of the entire data generated so far.

Towards this integration exercise, some new initiatives are introduced in the analysis and modeling steps. As a first step, large number of data segments, more than that used in previous on-land and seafloor studies, were reprocessed by the robust regression method to determine interstation vertical and horizontal field transfer functions at a wide range of periods. The vertical transfer functions when displayed in the form of induction arrows help to define zones of anomalously high conductivity. Further, the horizontal transfer functions at seafloor sites, when examined 

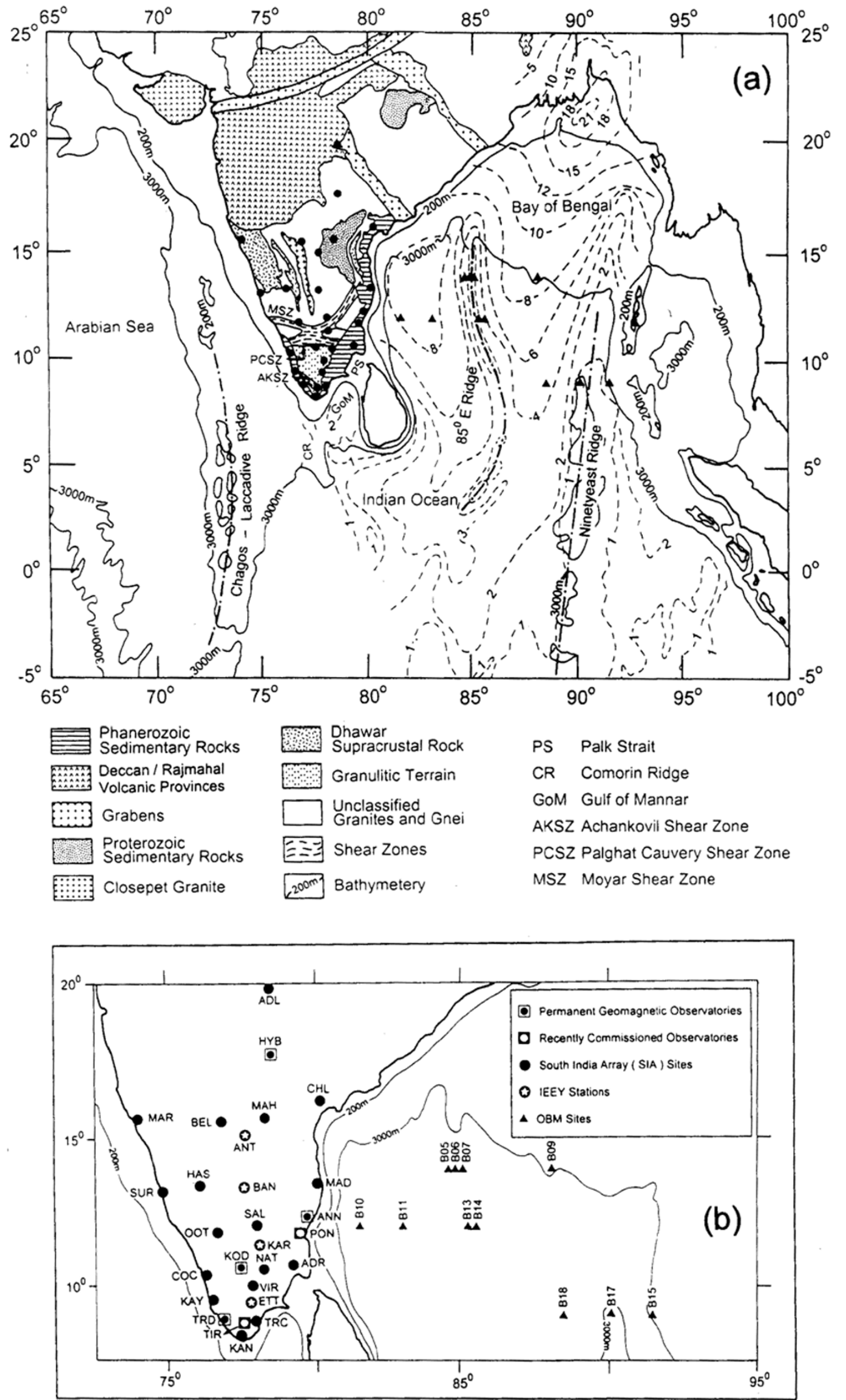

Fig. 1. (a) Locations of the on-land and seafloor magnetometer sites superimposed on geology and regional tectonic elements of south India and surrounding sea (after GSI (1993), Drury et al. (1984) and Curray and Munasinghe (1991)). Sediment isopachs (km) in Bay of Bengal are given by dotted line (Curray et al., 1982). (b) On-land and seafloor magnetometer coverage obtained during different campaigns in south India and Bay of Bengal. The 3 character stations codes are shown. 


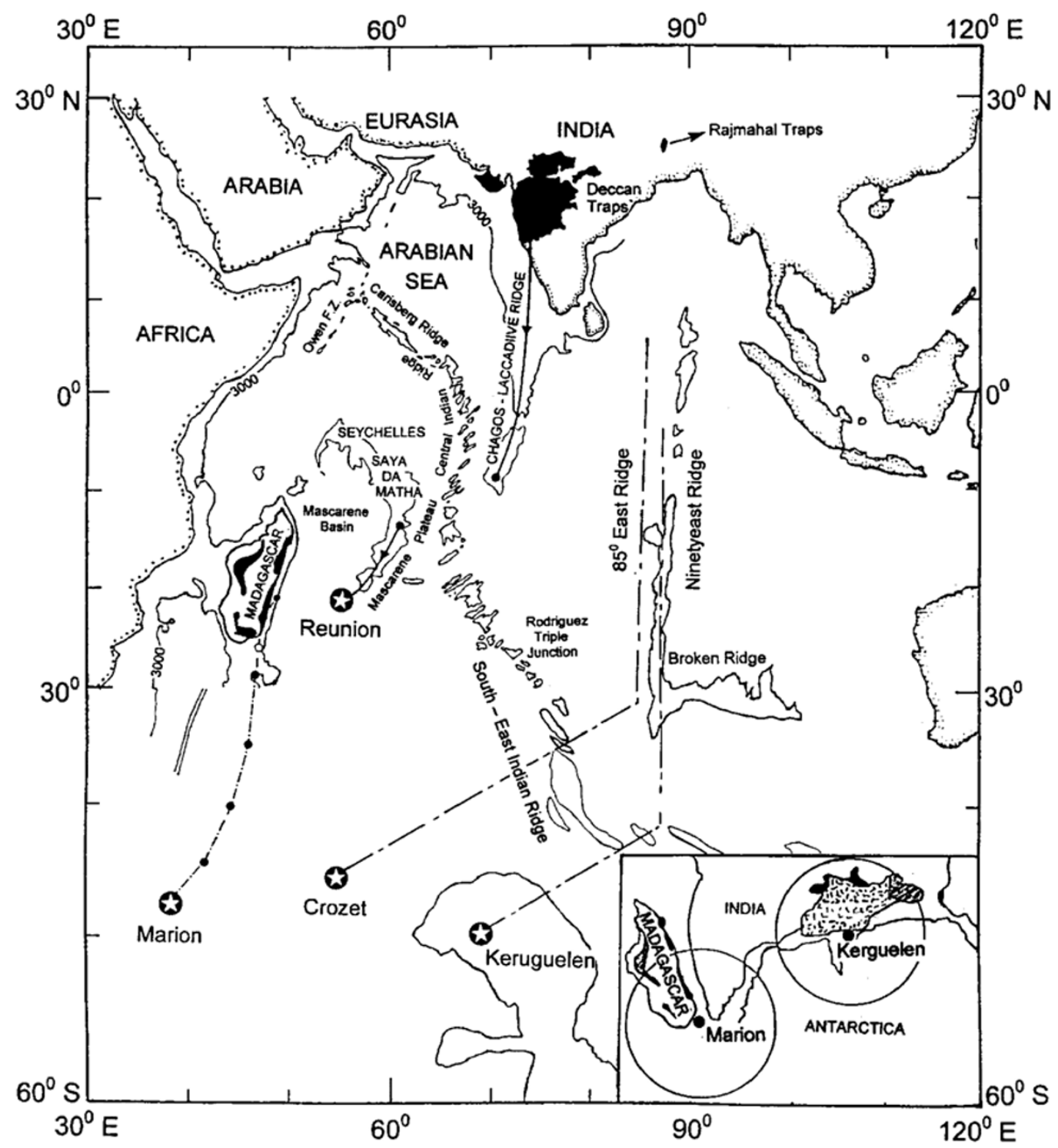

Fig. 2. The map showing the positions of different plume heads (a) Marion (b) Reunion (c) Crozet and (d) Keruguelen and ridges formed during the transit of the Indian plate over them (redrawn from Richards et al., 1989). Inset shows the area affected by the outburst of Marion Plume that led to the separation of Madagascar from India (Storey, 1995).

in the form of anomalous horizontal field ellipses, provided an effective mode to characterize shielding effect due to seawater as well as effect of current concentration in thick sedimentary columns on seafloor magnetic measurements. We finally used the noted anomalous signatures to develop a thin sheet conductance model for the entire region including the peninsular India and the Bay of Bengal. In variance with the previous attempts, the thin sheet model developed incorporated a more realistic conductivity-depth distribution beneath the thin sheet. The lateral conductivity variations in the thin sheet itself are constrained by the nature of allied geophysical anomalies.

\section{Geology and Tectonics}

Surface geology and tectonic elements of peninsular India, Bay of Bengal and surrounding ocean are shown in Fig. 1(a) (after GSI, 1993; Norton and Sclater, 1979; Curray et al., 1982; Drury et al., 1984; Curray and Munasinghe,
1991). The south India Peninsula is divided into three major tectonic elements, i.e. Dharwar craton, Eastern Ghats and the South Indian Granulite (SIG) province. The Dharwar craton is divided into western and eastern blocks by northsouth trending Closepet granite (Radhakrishna and Vaidyanadhan, 1997). The Dhawar craton is separated from the SIG terrain in the south by major shear zones, viz., Palghat Cauvery shear zone (PCSZ), Mayor-Bhavani shear zone (MSZ). Further south, SIG is cut by deep-seated Achankovil shear zone (AKSZ) (Ramakrishnan, 1993).

The major tectonic features underlying the Bay of Bengal include deep-sea fans, subduction zones and aseismic ridges namely $85^{\circ} \mathrm{E}$ and Ninetyeast Ridges. All these tectonic features are inherited from the breakup of eastern Gondwanaland and the subsequent transit of the Indian plate over a number of hotspots in the Indian Ocean (Fig. 2). Ninetyeast Ridge defines the northward path of the Indian plate as it moved away from the Kerguelen hotspot during 80 
$40 \mathrm{Ma}$. The ocean drilling legs 22 and 121 have confirmed the hotspot origin of the Ninetyeast Ridge (Peirce, 1978; Duncan and Richards, 1991; Royer et al., 1991; Weis et al., 1991). Similarly, the $85^{\circ} \mathrm{E}$ Ridge running parallel to the Ninetyeast Ridge and almost buried under the sediments of Bengal fan, evolved due to the interaction of the Indian plate with the Crozet hotspot (Curray and Munashinghe, 1991; Ramana et al., 1997; Subrahmanyam et al., 1999). The extended chain of submarine volcanic islands, ChagosLacadive ridge system, in the western margin and stretching to the proximity of central Indian Ocean, define the track of the Reunion hotspot.

The most intensive phase of the plume-lithosphere interaction are marked by the outburst of the plume head, leading to large-scale eruptions. The Rajmahal traps in the northeast and Deccan traps in central western parts of the India has been shown to be the manifestation of the outburst of Crozet/Kerguelen and Reunion Plumes around $115 \mathrm{Ma}$ and 65.5 Ma respectively. In addition the southern most part of the Indian sub-continent was affected by the Marion Plume outburst around $89 \mathrm{Ma}$ (inset in Fig. 2) that led to the separation of Madagascar from India.

\section{Data Sources}

The locations of magnetometer sites whose data are integrated in the present study are shown in Fig. 1(b). The entire coverage has been obtained through various arrays operated over different periods, scanning the last two decades and using a variety of magnetometers. Much of the coverage in peninsular India was obtained in a single large-scale South India Array (SIA) when twenty-one Gough-Reitzel types of magnetometers were deployed simultaneously (Thakur et al., 1986). Five permanent geomagnetic observatories in this part of peninsula formed regular grid points of the SIA. As a part of the International Equatorial Electrojet Year (IEEY), deployment of digital Fluxgate magnetometers at five temporary stations augmented the existing latitudinal chain of permanent magnetic stations in peninsular India (Arora et al., 1993). In recent years, Pondecherry (PON) and Tirunelveli (TIR) have replaced geomagnetic observatories at Annamalainagar (ANN) and Trivandrum (TRD) respectively. The data from these new observatories are also included in the present integrated study of transient variations.

The deployment of ocean bottom magnetometers in Bay of Bengal was carried out in three independent campaigns. The first two campaigns in 1991 and 1992 were across the $85^{\circ} \mathrm{E}$ Ridge, along $14^{\circ} \mathrm{N}$ and $12^{\circ} \mathrm{N}$ latitude, whereas in the third campaign during 1995, the profile cut across the Ninetyeast Ridge along $9^{\circ} \mathrm{N}$ latitude. In each campaign, five OBMs were deployed on linear profiles extending from the western flank to the eastern flank of the ridges. The seafloor site B10 and B15, however, were located respectively close to the eastern continental margin and near the northern extension of Sunda Arc and Andaman and Nicobar island Chain. For technical reasons, data were lost at seafloor sites B08, B12 and B16, and hence are not included in the present exercise.

The period and duration of field operation, type of magnetometer employed, field components measured (XYZ or
DHZ) and mode of data acquisition (analog or digital) are detailed in papers reporting the first results. For the present study, 1 min values, reduced to a geographic co-ordinate system, i.e. north $(X)$, east $(Y)$ and vertical $(Z)$ components, were employed. A large part of the area covered by the magnetometers falls under the influence of the equatorial electrojet. The presence of the equatorial electrojet, during daytime, causes external current sources to be highly nonuniform. This puts restrictions on the use of daytime data, as all GDS interpretation techniques presuppose the source field to be uniform. Given this limitation, we have used only nighttime segments in the calculation of period-dependent transfer functions.

\section{Data Analysis}

\subsection{Inter-station inter-component transfer functions}

In principle, magnetovariational fields observed at any recording site can be considered to be composed of normal and anomalous parts (Schmucker, 1970). Suppose $X_{n}$, $Y_{n}$ and $Z_{n}$ represent the components of the normal field, then magnetic field components at field sites $\left(X_{s}, Y_{s}\right.$ and $Z_{s}$ ) can be separated into normal and anomalous parts (e.g. $X_{s}=X_{n}+X_{a}$ ). In such case, frequency-dependent interstation transfer functions that relate the anomalous field components at a given site with the normal field components can be expressed as:

$$
\left[\begin{array}{c}
X_{a} \\
Y_{a} \\
Z_{a}
\end{array}\right]=\left[\begin{array}{lll}
T_{x x} & T_{x y} & T_{x z} \\
T_{y x} & T_{y y} & T_{y z} \\
T_{z x} & T_{z y} & T_{z z}
\end{array}\right]\left[\begin{array}{c}
X_{n} \\
Y_{n} \\
Z_{n}
\end{array}\right] .
$$

Under the assumption of uniform source field for short period fluctuations, when $Z_{n} \rightarrow 0$ and $Z_{s} \sim Z_{a}$, the vertical field transfer functions $\left(T_{z x}\right.$ and $\left.T_{z y}\right)$ can be expressed by a linear combination of two horizontal components:

$$
Z_{a}=Z_{s}=T_{z x} \cdot X_{n}+T_{z y} \cdot Y_{n}
$$

Similarly the anomalous horizontal field transfer functions $\left(T_{x x}, T_{x y}\right.$ and $\left.T_{y x}, T_{y y}\right)$ take the form:

$$
\left[\begin{array}{c}
X_{a} \\
Y_{a}
\end{array}\right]=\left[\begin{array}{ll}
T_{x x} & T_{x y} \\
T_{y x} & T_{y y}
\end{array}\right]\left[\begin{array}{c}
X_{n} \\
Y_{n}
\end{array}\right] .
$$

In an alternative approach, the total horizontal fields transfer functions summarizing the relation between total horizontal fields at a given site and normal field components can equivalently be expressed as

$$
\left[\begin{array}{c}
X_{s} \\
Y_{s}
\end{array}\right]=\left[\begin{array}{cc}
T_{x x}+1 & T_{x y} \\
T_{y x} & T_{y y}+1
\end{array}\right]\left[\begin{array}{c}
X_{n} \\
Y_{n}
\end{array}\right] .
$$

Drawing an equivalence of Eq. (4) with the magnetotelluric relation between electric and magnetic fields, Honkura et al. (1989) noted that total horizontal transfer functions could be used to define H-skew as follows

$$
\text { H-skew }=\frac{\left|T_{x y}-T_{y x}\right|}{\left|T_{x x}+T_{y y}+2\right|} .
$$

It can be easily verified that the H-skew is invariant under the rotation of measuring axis. The numerator in Eq. (5) 

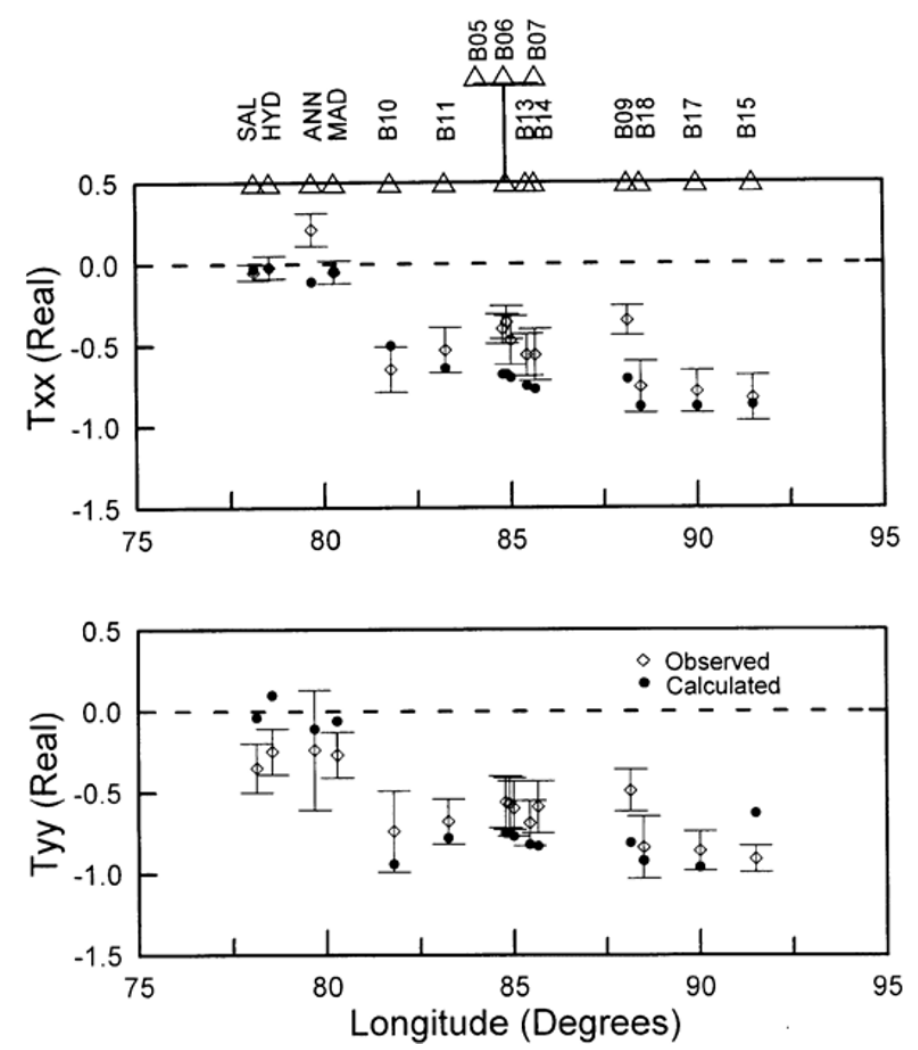

Fig. 3. Observed and calculated magnitude of horizontal transfer functions $\left(T_{x x}\right.$ and $\left.T_{y y}\right)$ along a profile extending from the peninsular India to the Bay of Bengal. The observed values are plotted with associated error bars.

vanishes if the earth structure is 1-D or 2-D and hence can be used as an indicator for dimensionality, in the same manner as the skew in magnetotellurics.

\subsection{Selection of the normal station}

It is obvious from Eqs. (2)-(3) that the calculations of inter-station transfer functions require simultaneous observations at a field station and the reference station such that fields at the later can be regarded as 'normal'. This condition is satisfied if the station is situated above a horizontally stratified earth structure (1-D) and is sufficiently distant from any lateral electrical discontinuity. The numerical estimation of vertical and horizontal field inter-station transfer functions for SIA and IEEY sites were carried out using the magnetic fields at Bangalore (BAN) as a measure of normal fields. The earlier analysis and interpretation of SIA data had shown that horizontal fields at Bangalore are free from the effects of currents concentration in structures marked by strong lateral variations in conductivity (Thakur et al., 1986).

For the seafloor campaigns, simultaneous data from Bangalore were not collected. However, during the seafloor campaigns in 1991, 1992 and 1995, a land reference station was con-currently operated at stations Selam (SAL), Annamalainagar (ANN) and Tirunelveli (TIR) respectively. The results reported by Joseph et al. $(1995,2000)$ and Subba Rao et al. (2000) have used data from these reference sites in reducing and interpreting data from the seafloor sites. The horizontal fields particularly at the station Annamalainagar (even to that matter at Tirunelveli) have earlier been shown to contain significant anomalous fields (Nityananda et al.,
1977). Some test calculations showed that choice of reference site is critical in the sense that reduced transfer functions at mobile sites tend to be biased if the horizontal fields at the reference site are highly anomalous, such as Annamalainagar. As against this when data from an alternative near normal site (e.g. Hyderabad-HYB or Salem-SAL) were used, the reduced transfer functions do not differ much from those obtained treating Bangalore as normal site. Given this evidence, in the present study, the transfer functions for the seafloor sites are calculated with respect to the fields at Hyderabad (for 1992 and 1995 arrays) and Salem (1991 array). 4.3 Numerical estimation

Both horizontal and vertical field transfer functions are calculated using the principle of robust regression as described in Egbert and Booker (1986). For the seafloor campaigns, some 8-10 nighttime segments, each of $512 \mathrm{~min}$ values, were used. For the IEEY and SIA arrays, the number of events used varied between 15 and 20. In addition, some band averages were used so that enough degrees of freedom were available for reliable statistical evaluation of transfer functions. In all, both vertical and horizontal field transfer functions are calculated for ten selected periods between 16 to $171 \mathrm{~min}$.

\subsection{Graphical representation of vertical and horizontal transfer functions}

The information contained in vertical transfer functions concerning the nature of conductivity distribution is now routinely extracted from maps of the induction arrows. However, no common graphical method is followed in portraying horizontal transfer functions that displays the char- 

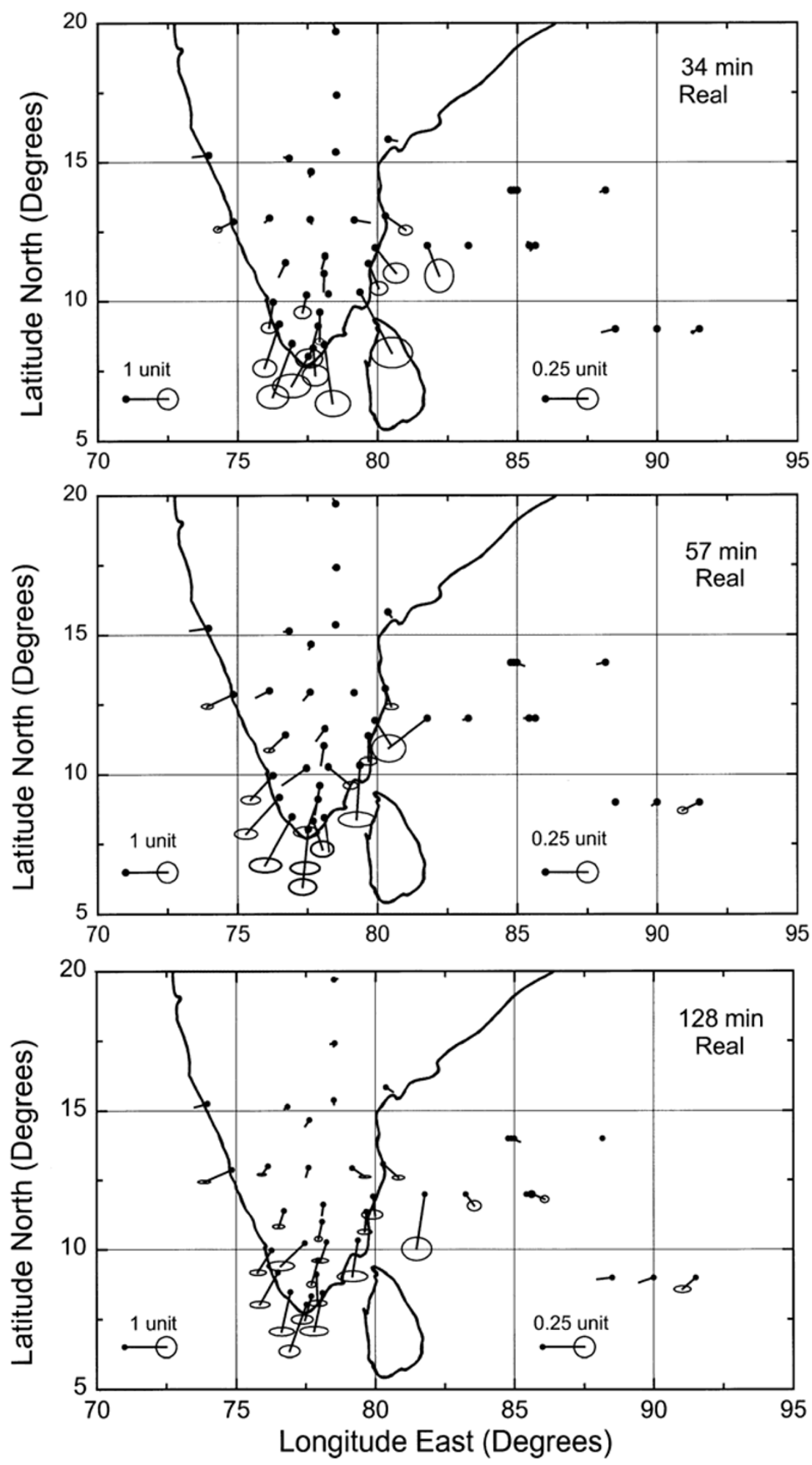

Fig. 4. Observed real and quadrature induction arrows together with the error ellipses for the three indicated periods. Note that arrows at seafloor sites are drawn at an enlarged scale of four times.

acter of the anomalous field or electrical conductivity structures. Given that horizontal field transfer functions are found to be important diagnostic tool to estimate shielding effect due to seawater as well as effects of induced currents in the sedimentary columns on the seafloor data, we have followed two alternative approaches. In the first approach, the values of two prominent elements of horizontal transfer func- tions ( $T_{x x}$ and $T_{y y}$ ) are plotted on a pseudo profile extending from the land to oceanic region (Fig. 3). Taking errors into account, results show significant attenuation of horizontal fields at seafloor sites. In the second approach, a method developed by Beamish (1982) and refined by Fujiwara and Toh (1996) is adopted. Here, information contained in all elements of horizontal field transfer functions is displayed by 

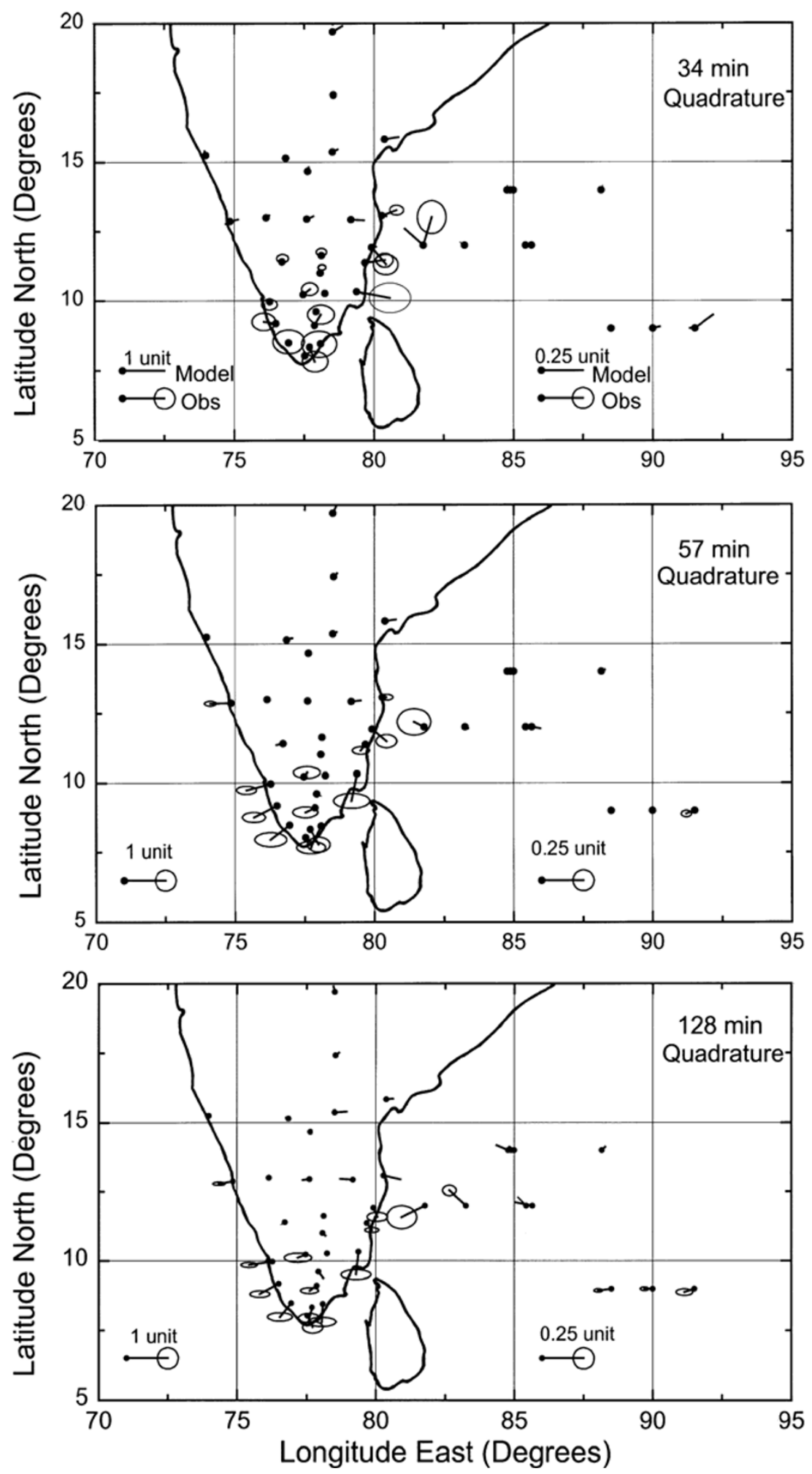

Fig. 4. (continued).

way of the rotation ellipses of anomalous horizontal field.

If we consider the normal field at a given frequency has unit amplitude and is directed (polarized) along angle $\theta$ anticlockwise with respect to east, i.e.

$$
\left(X_{n}, Y_{n}\right)=(\sin \theta, \cos \theta) ; \quad 0^{\circ} \leq \theta \leq 360^{\circ} .
$$

The components of anomalous field ' $a$ ' are given by

$$
a=\left[\begin{array}{c}
X_{a} \\
Y_{a}
\end{array}\right]=\left[\begin{array}{ll}
T_{x x} & T_{y y} \\
T_{y x} & T_{y y}
\end{array}\right]\left[\begin{array}{c}
\sin \theta \\
\cos \theta
\end{array}\right] .
$$

The estimated $X_{a}$ and $Y_{a}$ for a given $\theta$ are plotted as a point in the horizontal plane. As the angle is changed, each point traces out the locus of an ellipse, referred to as the anomalous ellipse of the horizontal transfer functions. The radii 

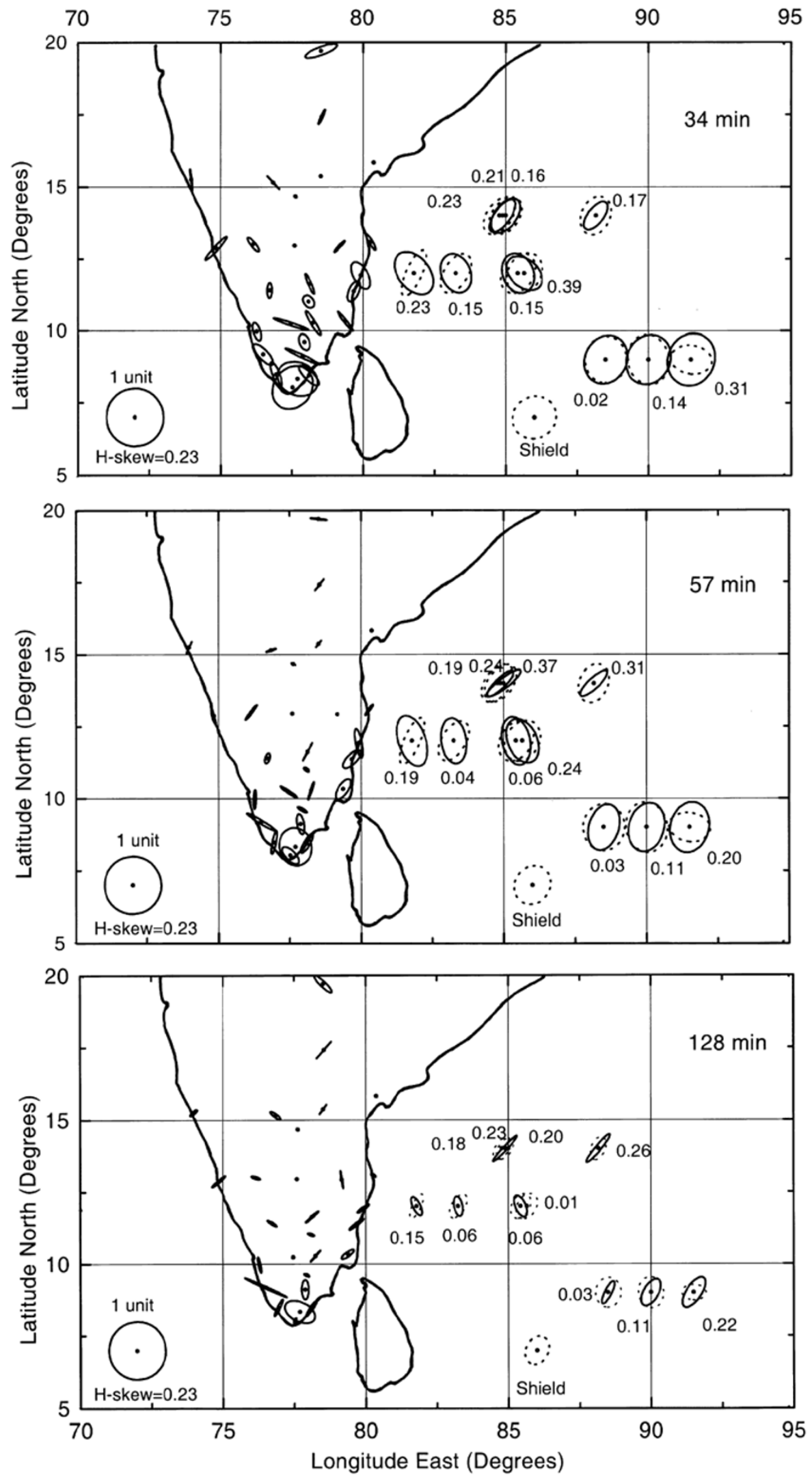

Fig. 5. Ellipses of anomalous current flow at all sites, derived from horizontal transfer functions, at the three specified periods. Numbers alongside the ellipses at seafloor sites denote H-skew values. Ellipses with a broken curve denote the shielding effect calculated from thin sheet model. 
of ellipses are proportional to the anomalous fields. It may be recalled that although external geomagnetic variations induce currents normal to the polarization of external source fields, the direction of the electrical current may be deflected by local or regional conductivity structure. The direction of the maximum anomalous current, which tends to coincide with the strike direction of the high conductivity structure, is normal to the major (or minor) axis of the anomalous ellipse. In the adoption of this graphical method of representing the horizontal field transfer functions, the anomalous ellipse of horizontal fields is therefore rotated $90^{\circ}$ anticlockwise so that the major axis of the rotated ellipse directly portrays the preferred direction of the path of anomalous current and, hence, defines the strike direction of the structure controlling the path of anomalous currents. Since each element of Eq. (6) is complex, one obtains a pair of ellipses corresponding to the real and imaginary parts. In the present case, the imaginary part at most sites is invariably much smaller than the real counter part and do not provide any additional information than that is extracted from the real parts, we will present and discuss anomalous current ellipses corresponding to real parts only.

\section{Conductivity Image Building \\ 5.1 Induction arrows}

Figures 4(a), (b) show the real and quadrature induction arrows together with error ellipses for three periods at all stations. The Parkinson convention is adopted so that the arrows point towards the conductors. Induction arrows at all seafloor sites are quite small and are not found helpful in delineating lateral variation in conductivity, if any, beneath the seafloor. The large induction arrows at all coastal sites bring out the sharp conductivity contrast across the continent-ocean boundary. At 34 min period, the real induction arrows immediately on the east and west coast sites, above $12^{\circ} \mathrm{N}$ latitude, point at right angles to the coastline. This behaviour is consistent with a conventional coast effect, resulting from the concentration of induced current in conducting seawater. Below the latitude of $12^{\circ} \mathrm{N}$, particularly along the east coast, induction arrows at ANN, PON and ADR deviate significantly from the normal to the coastline and with SSE orientation point towards the Palk-Strait region. This anomalous directional behaviour constituted strong evidence to suggest a conductive structure along the Palk-Strait (Singh et al., 1977; Thakur et al., 1986). Further south, along the southern tip of the peninsula, the anomalously large real induction arrows have SW or SSW orientations and form evidence of a large-scale anomaly in the offshore region immediately SW of the southern tip of India. This regional anomaly, henceforth, is referred to as South India Offshore Conductivity Anomaly (SIOCA).

The above noted features of the real induction arrows at 34 min undergo certain directional changes with increasing period of the induction fields. The real induction arrows at ANN, PON, ADR etc., rotate gradually from their initial orientation at $34 \mathrm{~min}$ such that at periods of $57 \mathrm{~min}$ and above they tend to depict the directional pattern exhibited by the rest of the stations in the peninsula. This behavior brings out the regional character of the SIOCA.

The accompanying quadrature arrows for $34 \mathrm{~min}$
(Fig. 4(b)) and lower periods are invariably not significant and present a scattered pattern. Nonetheless as period increases, quadrarure arrows increase in magnitude and show stable direction (Fig. 4(b)). Although magnitudes of the quadrature arrows are still smaller $(<50 \%)$ than corresponding real arrows, their directional pattern tends to corroborate the conclusion made on the basis of real arrows that induction pattern at long periods is totally controlled by the SIOCA.

\subsection{Ellipses of anomalous current flow}

Figure 5 shows ellipses of anomalous current flow, for periods of $34 \mathrm{~min}, 57 \mathrm{~min}$ and $128 \mathrm{~min}$. An interesting features of the maps for $34 \mathrm{~min}$ and $57 \mathrm{~min}$ is that major axis of the ellipses at most coastal site closely follow the coast line. This is consistent with the coast effect arising due to the concentration of induced current in the seawater along the coastline. Anomalous current ellipses at inland stations are conspicuously small but show distinct directional alignment. At $34 \mathrm{~min}$, ellipses are oriented in NNW-SSE direction but swing to orient along the NE-SW direction at long periods of $57 \mathrm{~min}$ and $128 \mathrm{~min}$. This period-dependent alignment suggests that at shallow depths (short period) the anomalous current flow in peninsular part, though weak, is largely controlled by the tectonic elements of the Dharwar craton whereas at long periods (greater depths), the NE-SW trending Eastern Ghat Mobile Belt tends to control the flow path of the anomalous current.

In contrast to the inland stations, ellipses of anomalous current flow at all seafloor sites are large. Since seawater is highly conducting, the amplitudes of magnetovariational fields are attenuated at the seafloor. Therefore, the horizontal transfer functions at seafloor sites, determined with respect to the land station, provide a measure of the degree of the attenuation due to seawater, also called the shielding effect. Further inhomogeneous conductivity distribution beneath the seafloor will also contribute to the horizontal fields recorded at seafloor sites. The two noteworthy features of the observed ellipses at seafloor sites are: (i) the sizes of the anomalous ellipses are large at shorter periods and become smaller at longer periods. This is consistent with the period dependence of the shielding effect: (ii) The ellipses at any given period show considerable spatial variability both in size and orientation, perhaps indicating presence of lateral conductivity variation beneath seafloor in the Bay of Bengal. The relative importance of the shielding effect and seafloor conductivity changes is discussed later with recourse to numerical modeling results.

\section{Numerical Modeling}

To obtain the electrical conductivity distribution that accounts for the observed induction response, a 3-D thin sheet forward approach has been adopted. The efficacy of the thin sheet approach to model induction response, separately for peninsular India (Mareschal et al., 1987; Agarwal and Weaver, 1989) and Bay of Bengal (Joseph et al., 2000) has already been well documented. In that respect, the present attempt is an update of these previous exercises, in the sense that it incorporates induction measurements from a much larger area, additional sites and includes fresh constraints from recent geophysical investigations. 
(a)
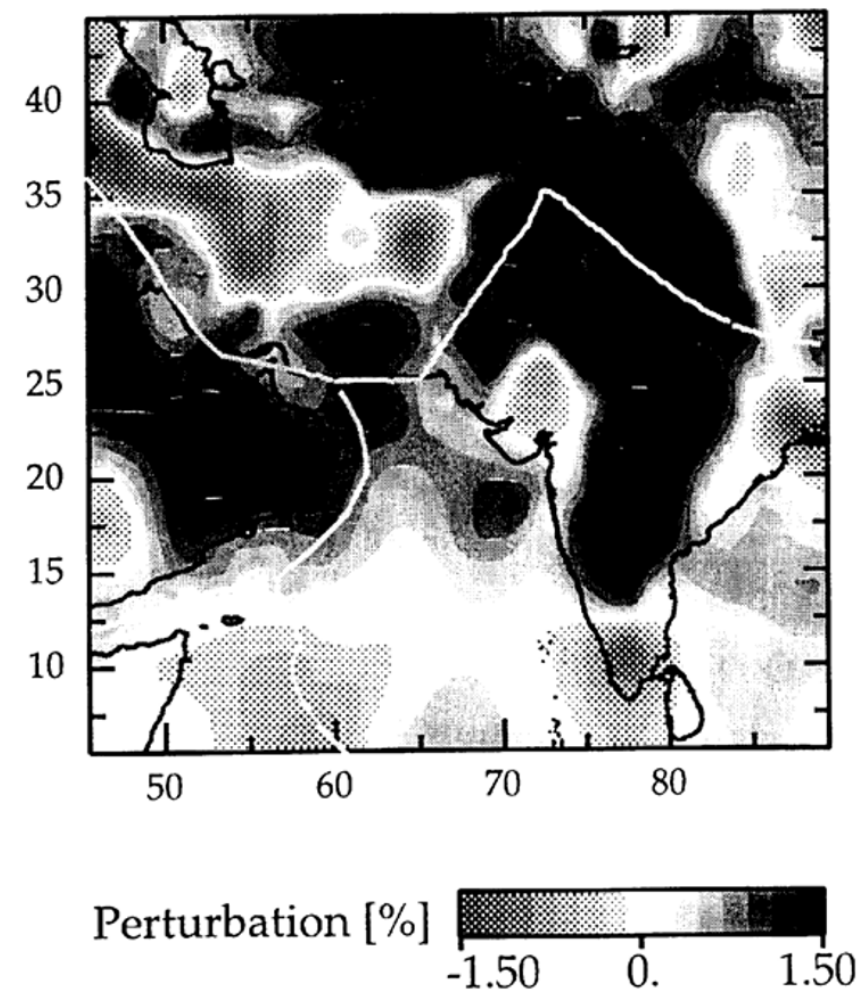

(b)

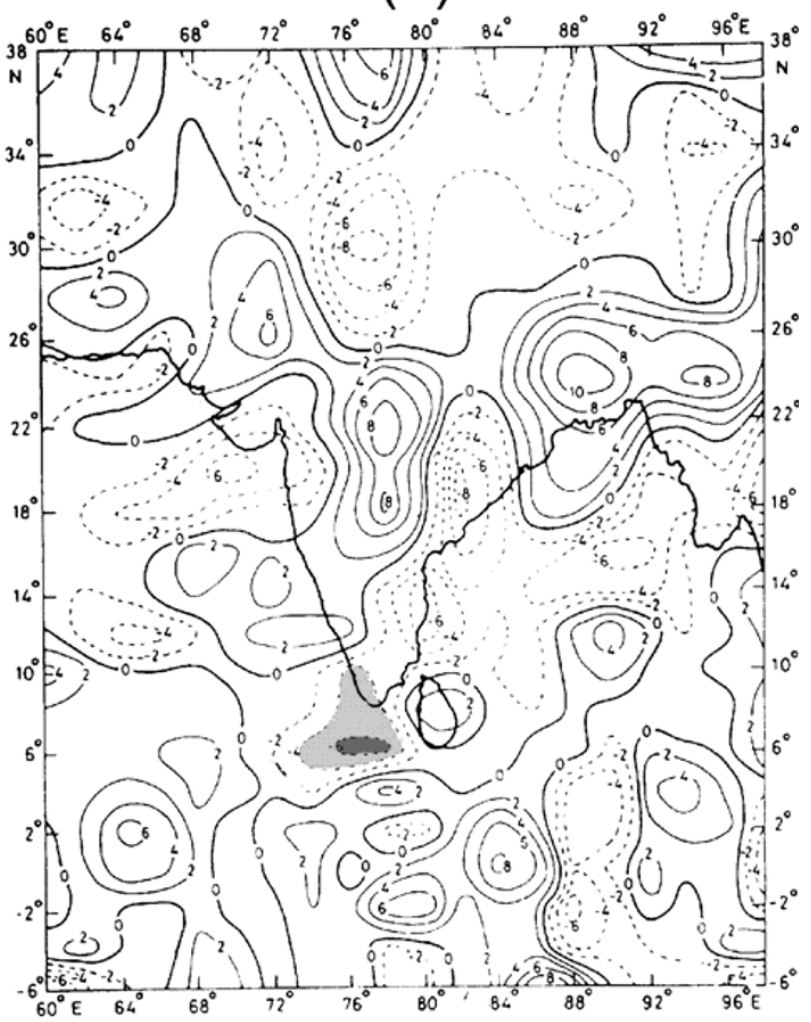

Fig. 6. (a) Map view of the $P$ wave velocities at the depth interval of $100 \mathrm{~km}$, indicating low-velocity zones centered at the southern tip of peninsula, western India (Cambay) and NE India (modified from Kennet and Widiyantoro, 1999). (b) Magnetization distribution map for Indian sub-continent derived from MAGSAT vertical field anomalies (after Singh et al., 1991).

To explain the induction pattern around the southern tip of India, earlier thin sheet models (Mareschal et al., 1987; Agarwal and Weaver, 1989) have emphasized geological features in the offshore region, immediately south of India. The model developed included a subsurface conductor beneath the Palk-Strait. A second conductor, perhaps related to the uprising of mantle material into deformed lower crust was placed under the Comorin Ridge, extending along the west coast. Mareschal et al. (1987) envisaged that the conductor included beneath Palk-Strait might be connected to the development of a rift system associated with the breakup of Gondwanaland (Naqvi et al., 1974; Burke et al., 1978) while the conductor south of India possibly marked some kind of triple junction between Comorin Ridge, the IndoCeylon Graben and west coast rifting. The anomalous character of the lithosphere immediately south of India has been also indicated by $P$-wave seismic tomography (Kennet and Widiyantoro, 1999) as well as from a magnetization distribution map deduced from the inversion of MAGSAT vertical field anomalies (Singh et al., 1991). The $P$-wave traveltime tomography of the Indian region has revealed three approximately cylindrical regions of lower seismic velocity down to a depth of $200 \mathrm{~km}$ (Fig. 6(a)). At the surface, the center of two low velocity anomalies correspond with the present exposure of the Deccan flood basalts and the Rajmahal traps, resulting from the outburst of the Reunion and Crozet/Kerguelen Plumes. The third low velocity zone (LVZ) is centered near the southern tip of the peninsula. Due to the unfavorable disposition of seismological stations and seismic events used in the inversion, there remains doubt on the exact location and extent of the third LVZ. However, the position corresponds well with the location of the Marion Plume outburst that led to the separation of India and Madagascar (Storey, 1995). The magnetization distribution map shown in Fig. 6(b), also brings out evidence of welldefined lows just south of Indian Peninsula and the Gulf of Cambay. One possible scenario is that the regions of low magnetization imply thin magnetic crust related to the rise of the Curie point isotherm. Comparison of Figs. 6(a), (b) shows that the centers of the low magnetization anomalies (LMA), both for South India and the Gulf of Cambay, are located south of the centers of the LVZs at upper mantle depths. The center of the LVZ in the Cambay region corresponds with the earliest alkaline magmatism that has a direct plume origin (Basu et al., 1993). This magmatism has been dated to $68.5 \mathrm{Ma}$ and so predates the flood basalts eruptions by at least 3.5 My. Given the northward migratory trend of greater India, the offset in the locations of LVZ and LMA can be reconciled as follows. The zone of lowered seismic velocity represents the remains of the initial interaction of the plume head with the base of lithosphere whereas the region of the low magnetization defines shallow areas affected by the final outburst of the plume. It seems plausible that large-scale upwelling, partial melt or thermal remobilization of crustal and mantle material associated with the Marion Plume that produce LVZ or LMA anomalies might also be 
the geological mechanism to enhance crustal/upper mantle conductivity and needed to explain the accentuation of the induction arrows observed in the southern tip of India. To test this hypothesis a fresh conductance map is devised that incorporates this new geophysical/geological information.

The updated conductance distribution model developed here considered an area of $0^{\circ}-20^{\circ} \mathrm{N}$ and $68^{\circ}-95^{\circ} \mathrm{E}$. The inclusion of such a large area in modeling facilitated complete representation of geological features of the Indian shield and surrounding oceans. This not only allowed incorporation of structures associated with the SIOCA, but the regional coverage was used to model large-scale distortion of induced currents at the land-sea boundary as well as shielding effects at the seafloor due to the seawater column. Wang et al. (1997) have demonstrated the affectivity of the thin sheet approach to model induction response of such a large area with reference to the entire Australian continent.

\subsection{Design consideration}

Thin sheet formulation confines all conductivity anomalies to a thin layer, with a laterally varying conductance. The sheet is underlained by a layered conductivity structure. In the previous models for South India, developed by Mareschal et al. (1987) and Agarwal and Weaver (1989), the 1-D structure (substratum) beneath the thin sheet was approximated by two layers. In both modeling exercise, the top layer had a total thickness of $30 \mathrm{~km}$ (including the thickness of the thin layer). Mareschal et al. (1987) had assigned a resistivity of $1000 \Omega \mathrm{m}$ to this layer that is compatible with resistive character of the crust in this shield region. In comparison, Agarwal and Weaver (1989) adopted a little lower value of $200 \Omega \mathrm{m}$ to satisfy the thin sheet conditions implicit in their algorithm. The bottom layer was a half-space with resistivity of $10 \Omega \mathrm{m}$. In these models, the two layers represented respectively the crust and the mantle. The interface simulated the Moho as a first order electrical discontinuity. Magnetotelluric (MT) soundings carried out in regions of different continental lithosphere do not reveal the Moho as a major electrical discontinuity. Instead, MT investigations show the lithosphere-asthenosphere boundary as sharp electrical discontinuity. One of the artifacts of including such a high conducting layer in the substratum, at such a shallow depth of only $30 \mathrm{~km}$, is to dampen the induction response of the anomalous structure in the thin sheet (Mareschal et al., 1987; Arora, 1990). In order to produce induction response compatible with the observations requires assignment of artificially high conductances to the thin sheet cells. MT investigations, initiated recently in the Dharwar craton, South India, have shown that the lithosphere-asthenosphere transition is located at a depth of more than $150 \mathrm{~km}$ (Arora et al., 2001). In agreement with this observation, the 1-D structure beneath the thin sheet is represented by a $150 \mathrm{~km}$ thick lithosphere of $1000 \Omega \mathrm{m}$ with the half-space of $10 \Omega \mathrm{m}$ below simulating asthenosphere.

Since one of the objectives of the thin sheet model is to investigate the effect of the seawater column on the seafloor EM measurements, the thin sheet was assigned a thickness of $3 \mathrm{~km}$, corresponding to the depth of seawater at OBM locations. The rectangular modeling area of $20^{\circ} \times 27^{\circ}$ is divided into $40 \times 54$ grid with node spacing of $55 \mathrm{~km}$. This node spacing is comparable to that adopted in earlier stud- ies and allows adequate inclusion of small-scale structures. The initial conductance distribution, adopted for the regional model, depicted the lateral variations in conductivity arising from land and seawater. Different ocean depths varying from $200 \mathrm{~m}$ to $3000 \mathrm{~m}$, defined by the bathymetry, are included in the calculations of the conductance for the offshore cells. Following Mareschal et al. (1987), the grid cells located between land and the $200 \mathrm{~m}$ isobath have been modeled as if covered by $200 \mathrm{~m}$ of water for conductance calculations. Likewise, all cells between $200 \mathrm{~m}$ to $1000 \mathrm{~m}$ isobaths and $1000 \mathrm{~m}$ to $2000 \mathrm{~m}$ are assumed to include respectively $1000 \mathrm{~m}$ and $2000 \mathrm{~m}$ of water. Beyond $2000 \mathrm{~m}$ bathymetric contour, all cells are assumed to have water column of $3000 \mathrm{~m}$. For purpose of conductance calculations, seawater resistivity is taken to be $0.33 \Omega \mathrm{m}$ (Heinson and Lilley, 1993). The land parts of peninsular India, Sri Lanka and the chain of islands in Andaman-Nicobar, Lakshadweep and Sunda arc etc, are all represented by material of $1000 \Omega \mathrm{m}$.

\subsection{Model calculations}

Thin sheet calculations are made using the algorithm developed by Vasseur and Weidelt (1977). This formulation requires that the domain modeled must be entirely surrounded by a region of normal structure. In the regional model, normal structure is represented by a conductive medium of $3300 \mathrm{~S}$, equivalent to seawater of $1 \mathrm{~km}$ depth. The only unrealistic boundary is the northern limit of the grid. This edge effect is not likely to be serious, as it is placed sufficiently distanced from the observational domain (Mareschal et al., 1987). Numerical solutions are worked our for two conductance distribution: (i) non-uniform thin sheet representing lateral variations arising from land and seawater of variable depths, as described earlier; (ii) additional subsurface structures are included in the region of Palk-Strait and in the offshore region, as constrained by supporting geophysical inputs, to account for anomalous induction effects associated with the SIOCA. The final thin sheet model devised is shown in Fig. 7. Conductance in different cells and other thin sheet parameters (thickness, grid size etc.) satisfied thin sheet conditions, stipulated by Weaver (1982). Thin sheet calculations were made at periods of 34, 57 and $128 \mathrm{~min}$. At each period the EM response of the given conductance distribution is computed for the N-S and E-W polarization of the source field.

The magnetic field components were computed both on the top and bottom of the thin sheet. On the land, represented by material of $1000 \Omega \mathrm{m}$, the attenuation of diffusing EM waves within the thin sheet at the periods in question is negligible. So horizontal fields on the top or bottom side of the sheet are more or less the same. In the oceanic domain, however they show considerable differences between the top and bottom side of the sheet. In order that the model response can be compared directly with the observed response at the seafloor, we have used the magnetic field components for the lower side of the thin sheet. However, the induction arrows related parameters are computed using the horizontal fields at the node denoting the location of the normal site.

6.2.1 Induction effects of coastline and islands Figure 8 shows the real induction arrow pattern at $34 \mathrm{~min}$, corresponding to the conductance distribution model depicting lateral variation associated with land and seawater of vari- 


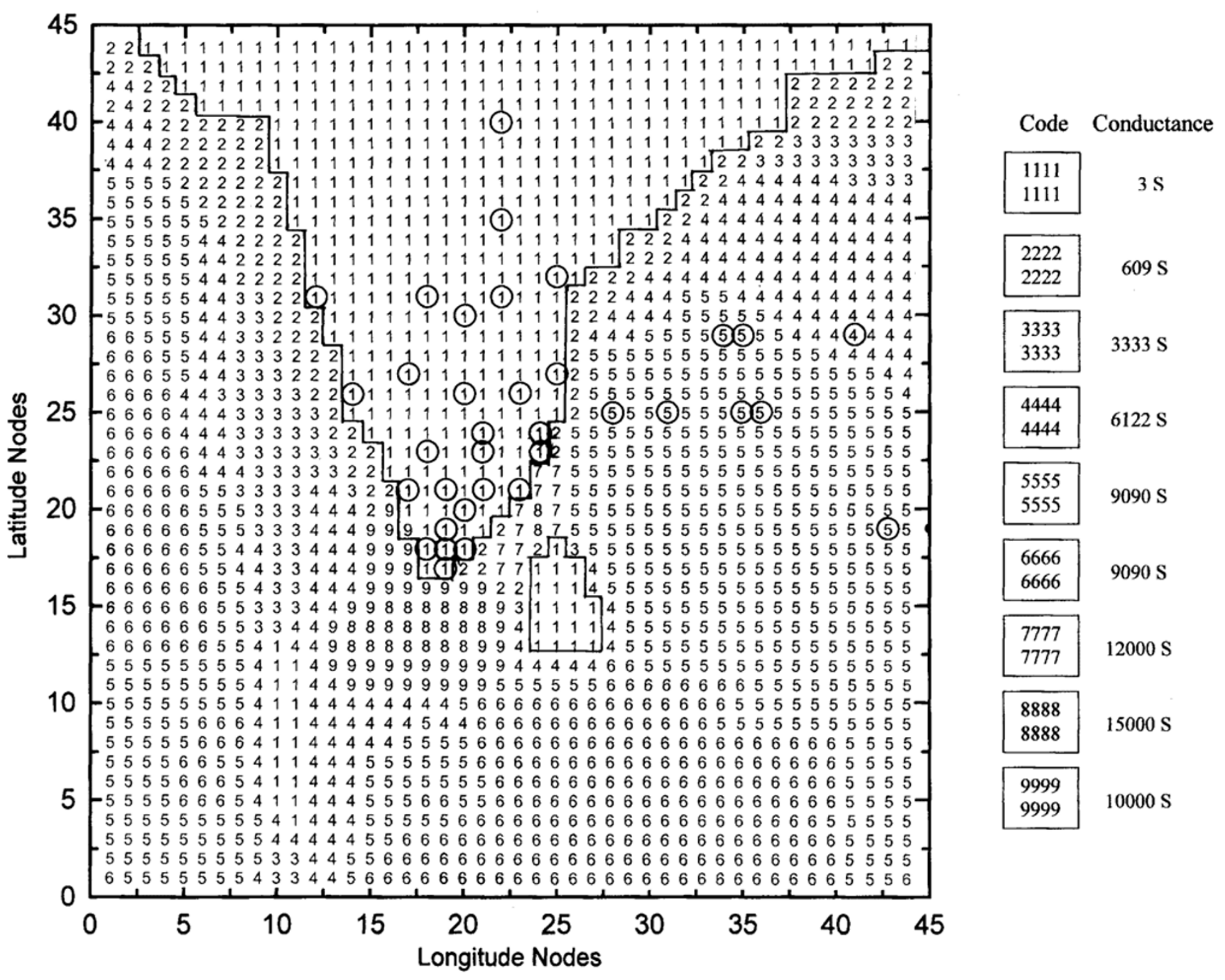

Fig. 7. Thin sheet conductance (coded) map for the south Indian peninsula, Bay of Bengal and surrounding oceans. Conductances assigned to different codes are also indicated. Cell codes 8 and 9 represents South India Offshore Conductivity Anomaly and Cell code 7 represents Palk-Strait conductivity anomaly.

able depth (i.e. Fig. 7 without anomalous cells 7, 8 and 9). The most dominant induction arrow pattern is seen at the land-sea transition and persists at all the periods. The magnitude of the induction arrows diminishes away from the coastline. However, the decay is faster landward where the coast effect vanishes within 1-2 grid points. Contrary to this, the coast effect decreases rather slowly seaward. But once away from the sloping continental shelf, i.e. in the region of deep-ocean, induction arrows are intangibly small. The presence of Lakshadweep islands in the Indian Ocean and Andaman-Nicobar islands near the eastern edge of the working grid produce strong perturbation in the flow path of induced currents in the oceanic region. As a result, the induction arrows are directed away from the landmass towards the deep ocean. The observed arrow pattern across the Ninetyeast Ridge is in agreement with this expected island effect and has nothing to do with the Ninetyeast ridge itself.

The induction arrow at all grid points, just four cells away from the edge of total working domain are negligibly small in magnitude. This behaviour indicates that calculated induction arrows at the actual observation sites are not affected in any significant manner by artificial normal structure that encloses the observational domain.

The model induction arrows reproduce well the directional and amplitude behavior of induction arrows observed on the east and west coasts of the Indian Peninsula, above the latitude of $12^{\circ} \mathrm{N}$. However, the model does not reproduce some of the well-developed directional characteristics of the induction arrows on the lower section of east coast. Also the magnitude of the induction arrows near the southern tip of the peninsula are substantially smaller than those observed in this part. This is due to the simple nature of the model, as it has not incorporated subsurface conductive structure warranted by the data. Our close-up model discussed in the later section, is aimed at explaining the complex induction pattern along the southern tip of peninsula.

6.2.2 Comparison of the observed and model response at seafloor sites The anomalous horizontal field transfer functions obtained from the thin sheet model are used to obtain ellipses of anomalous current. These are superimposed in Fig. 5 together with those derived from the observed data. The horizontal field transfer functions 


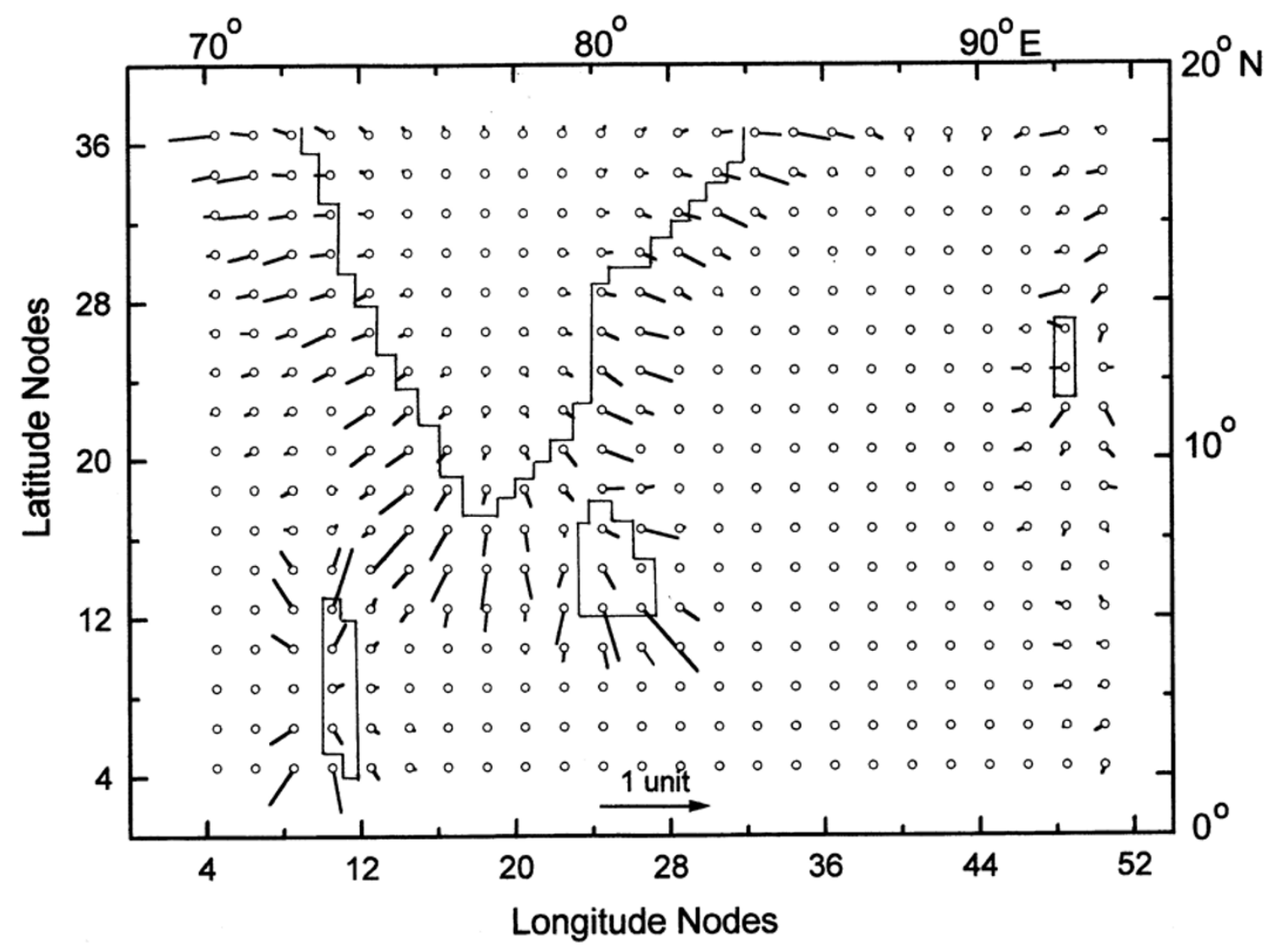

Fig. 8. Real induction arrows at period of 34 min corresponding to thin sheet model depicting lateral variation in conductances due to coastal boundaries and seawater of variable depth, i.e. without the inclusion of anomalous cells marked by codes 7, 8 and 9 in Fig. 7 . The arrows are shown for alternate grid points.

obtained from the model calculations are also included in Fig. 3. Since horizontal field values for the bottom side of the thin sheet are used, the calculated anomalous ellipses provide a measure of the shielding (screening) effect at seafloor sites due to the seawater. Figures 3 and 5 show that large part of the horizontal transfer functions at seafloor sites are accounted for by the shielding effects. However, part of the differences in the calculated and observed, after allowing for associated errors, may be due the contribution from the sediments underlying the sites. Across the Ninetyeast Ridge, where the thickness of sedimentary column is quite small, the observed and calculated ellipses, particularly at B17 and B18, match quite well, suggesting the observed behavior can primarily be explained in terms of the shielding effect. Another significant feature of the anomalous horizontal fields across the Ninetyeast Ridge is that skew value is largest at the eastern most station B15 and the values decrease systematically towards the west. Station B15 is very close to the Andaman-Sunda subduction zone where the oceanic lithospheric plate of Bay of Bengal with its overlying sediments subducts the Burmese plate. The lithospheric upwarp formed at the outer edge, due to the flexing of the subducting plate at the Sunda Arc, may perturb the flow pattern of the induced currents. The high skew value at B15 and its decaying trend to the west may be attributed to the perturbation of induced currents along the Sunda Arc. Skew values of the order of 0.3-0.5 are typical characteristic of 2-D structure.

As compared to the profile across Ninetyeast Ridge, the overall thickness of the sedimentary column as well as its variations are large across the central part of the Bay of Bengal, i.e. along the OBM profiles parallel to $12^{\circ} \mathrm{N}$ and $14^{\circ} \mathrm{N}$, is large. Therefore, the contribution of induced currents flowing in the sedimentary column to horizontal fields would be relatively stronger along the $12^{\circ} \mathrm{N}$ and $14^{\circ} \mathrm{N}$ profiles. These induced currents produce horizontal fields at seafloor sites, which are in an opposite sense to horizontal fields produced by currents in the seawater. The relatively smaller size of the observed ellipses of anomalous horizontal fields in the central part of the Bay of Bengal is consistent with the partial annulling of the shielding effect of seawater by currents concentrated in the sediments. It is also worthy of note that ellipses, particularly at stations located right over the $85^{\circ} \mathrm{E}$ Ridge (B06, B13) or in its immediate vicinity (B05, B07, B14) do not show any anomalous elongation in N-S direction as compared to the stations on the flanks, as one would have expected if the currents were concentrated right beneath the ridge axis. A critical examination shows that observed and calculated ellipses have distinctive differences only at B09, B10 and B11. At these places, the observed ellipses deviate from the calculated, such that the observed ellipses are aligned with the axis of sediment filled troughs on either side of $85^{\circ} \mathrm{E}$ Ridge. At these stations, the skew values, indicative of dimensionality, also tend to be rel- 

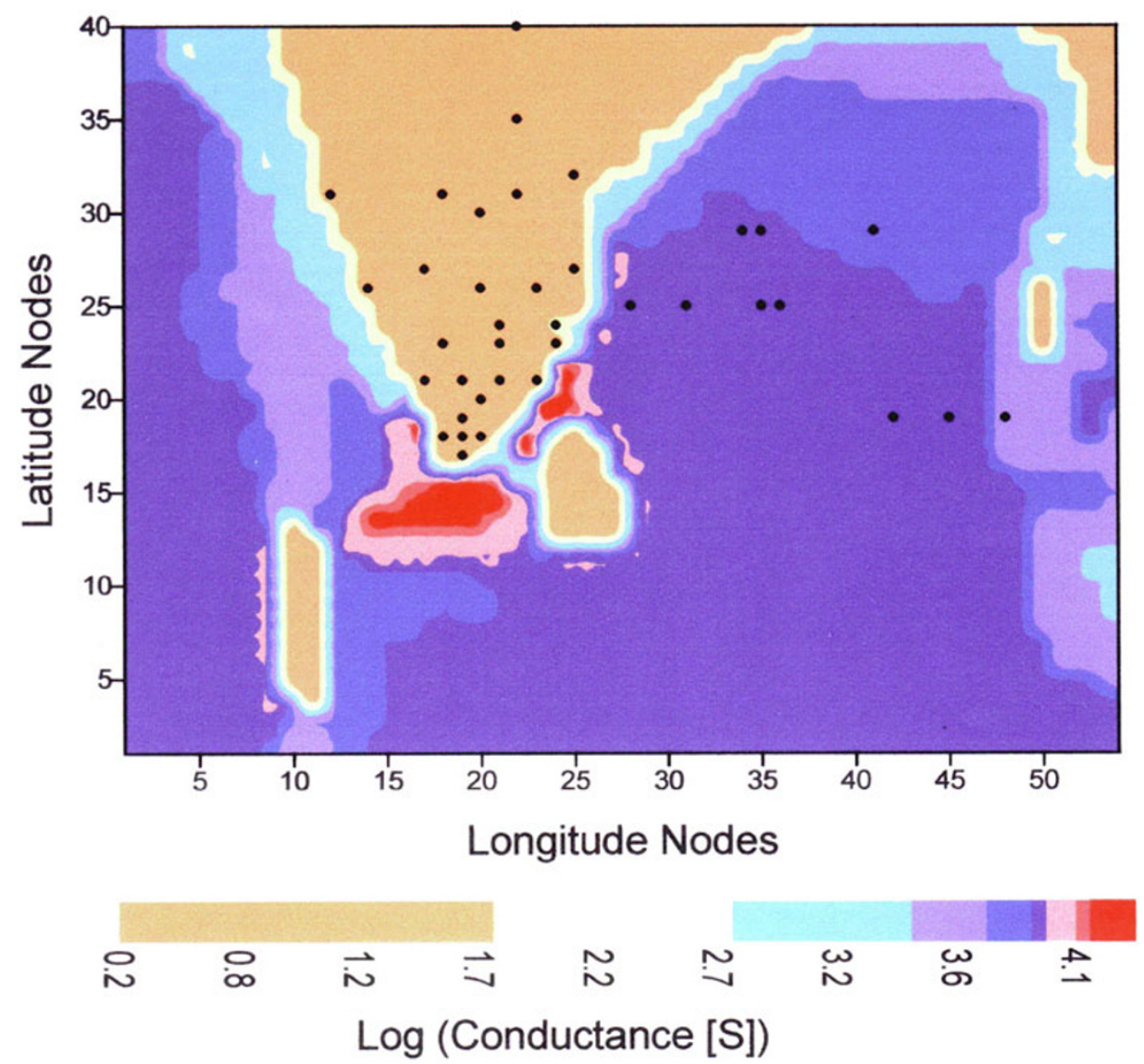

Fig. 9. The spatial variation of conductance (logarithmic scale) in and around peninsular India, deduced from thin sheet model covering an area of $0^{\circ}-20^{\circ} \mathrm{N}$ and $68^{\circ}-95^{\circ} \mathrm{E}$.

atively higher. This behavior favours that induced currents in sub-oceanic crust avoid flowing through the resistive $85^{\circ} \mathrm{E}$ Ridge and are concentrated in troughs filled with sediments reaching a thickness of the order of $8 \mathrm{~km}$, on either side of the ridge (see Fig. 1).

A more quantitative interpretation of the anomalous ellipses would need inclusion of the sedimentary column in this sheet model. The isopach map of the Bay of Bengal (Fig. 1) shows that sediment thickness varies from $2 \mathrm{~km}$, near the equator, to $22 \mathrm{~km}$ in the Bengal fan. These sediments are too thick to be incorporated into the thin sheet. Their representation as an independent layer beneath the thin sheet would invalidate the thin sheet condition, i.e. thickness of the sheet should be small compared to the skindepth in the underlying conducting layer. To alleviate these problems, Joseph et al. (2000) have recently developed a 3$\mathrm{D}$ model. Their results convincingly show that inclusion of sediments give a better fit to the observed response at the seafloor.

6.2.3 South India offshore conductivity anomaly model The schematic model developed to account for the induction pattern on the eastern coast and southern tip of the peninsula basically included two anomalous zones. The first zone represents the section of the crust/mantle that has been thermally remobilized or altered by Marion Plume outburst. The coded cells 8 and 9 (Fig. 7) outline this zone and their conductances were varied in several combinations to produce a response compatible with observations. The other anomalous zone marked by cells 7 represents the conductor beneath the Palk-Strait. The extent of this structure and its connectivity with first zone was tested by trial and error. The conductance values shown in Fig. 7, are the final values adopted in the thin sheet solution. The overall picture of the spatial conductance distribution is depicted in Fig. 9. The comparison of the model and observed induction arrows at all land stations is shown in Fig. 10 for the two periods. Given an allowance for the uncertainties associated with observationally reduced arrows and the simplifications involved in the numerical solution, the model and observed arrows compare well, both in direction and magnitude. The extent to which the SIOCA and Palk-Strait conductor account for the observed induction pattern at the southern part of the peninsula is further brought out in Fig. 11 by comparing the calculated real induction arrows with and without the SIOCA and Palk-Strait conductor. The induction response obtained without incorporating these two major conductive structures is substantially smaller than observed pattern. However, the inclusion of the SIOCA brings a close semblance between observed and calculated arrows, both in magnitude and direction. The fit is reasonably good near the southern tip where the strongest anomaly pattern is observed. More interestingly, the calculated arrows also reproduce the period dependence depicted by the observed real and quadrature arrows in the southern part (Fig. 10). How- 

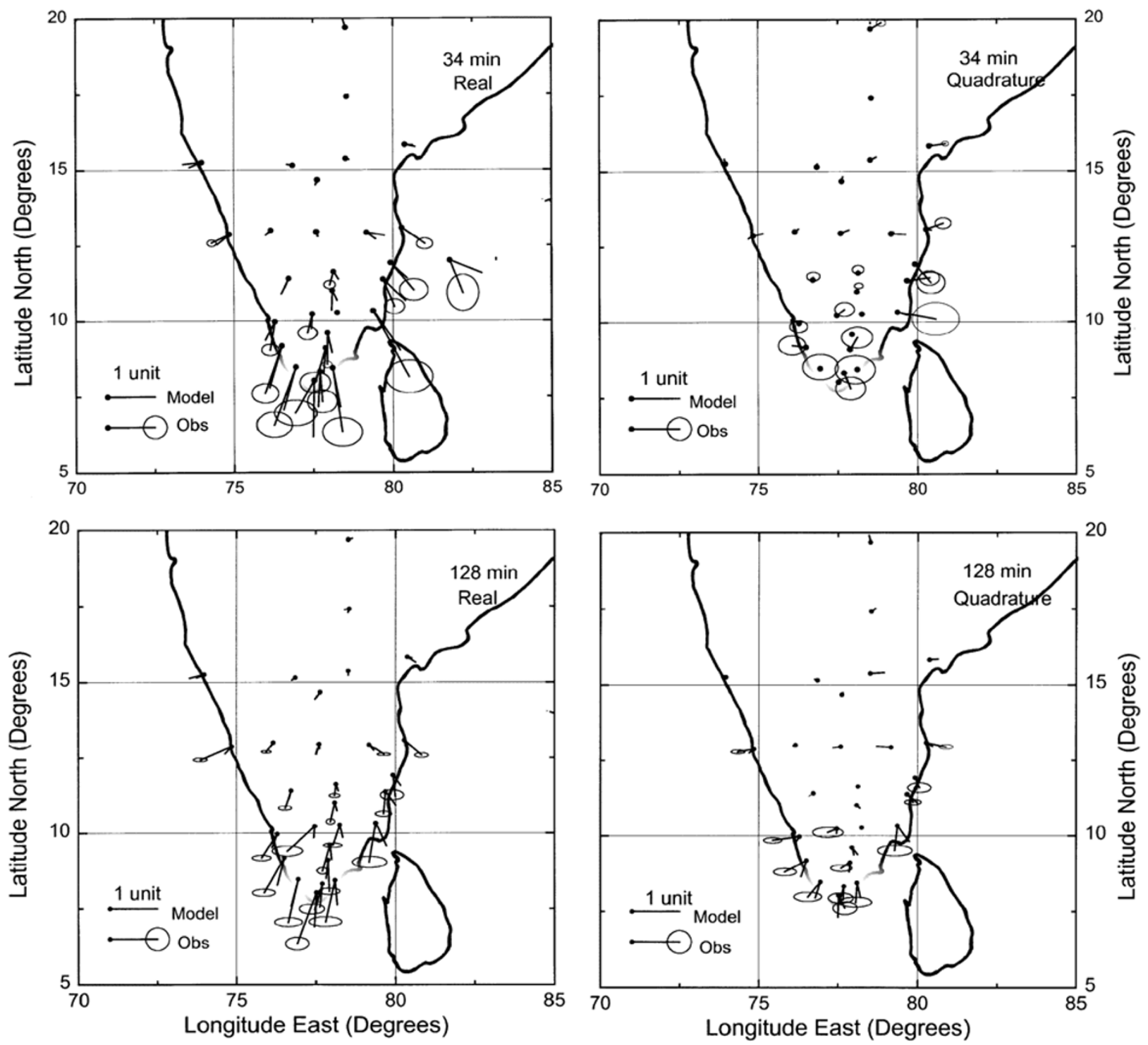

Fig. 10. Comparison between observed and modeled real and quadrature induction arrows for the conductance map shown in Fig. 7 at specified periods.

ever, the model response fails to reproduce adequately the rotational behaviour of real arrows seen on the east coast. This may be due to approximating the complex 3-D structure of the SIOCA by a simple heterogeneous sheet. 3$\mathrm{D}$ modeling, on the lines recently applied by Joseph et al. (2000) to Bay of Bengal data, may help to approximate the true geometry of the SIOCA. The spatial extent of the SIOCA, (codes 8 and 9 in Fig. 6(a)), matches well with the outline of the LMA. A conductor in the Palk-Strait was essential to produce large magnitude arrows on the east coast, particularly at ANN, PON, ADR, etc. As noted earlier by Marchael et al. (1987), the conductance of conductor along the Palk-Strait is required to be lower than that of the regional anomaly SW of the tip of India (SIOCA).

\section{Discussion and Conclusions}

The nature of the geomagnetic induction response across the $85^{\circ} \mathrm{E}$ and Ninetyeast Ridges does not show any enhanced conductivity along the ridge axis. The weak induction response seen across the $85^{\circ} \mathrm{E}$ Ridge can be attributed to the concentration of the induced currents in the sediment filled troughs, formed in response to the uplift of the ridge. The absence of a strong conductivity anomaly beneath the ridges signifies that the ridges, carved out from the transiting Indian plate by the thermal interaction of the plumes, are currently not marked by any thermal anomaly nor show the presence of fluids/volatiles released from plume inducted magmatic/metamorphic activities. The thin sheet model locates the source of the SIOCA in the offshore region, immediately SW of the tip of the Indian Peninsula. The correspondence of this SIOCA with the low velocity zone and low magnetization anomaly favours that these anomalies may be the relics of the Marion Plume outburst. Such a hypothesis is independently corroborated by induction anomalies recorded by the localized 9-station magnetometer array, carried out along the west coast of India (Arora and Reddy, 1991). It was found that despite a favourable location in relation to the N-S running coast line, the induction arrows at all stations were uniformly aligned in a NW direction, indicating a high conductivity anomaly beneath the area affected by 


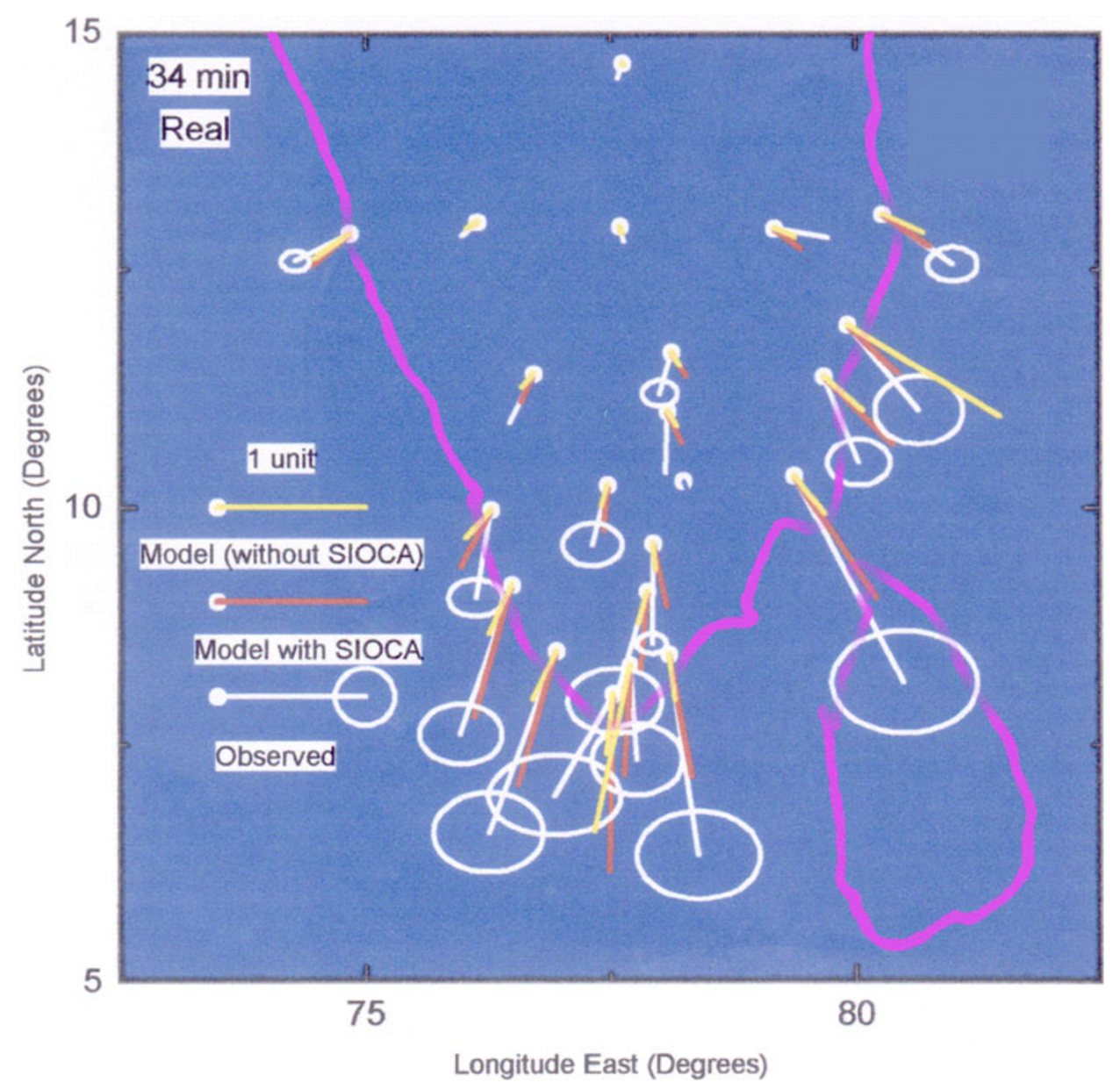

Fig. 11. Comparison of observed and calculated (with and without the SIOCA) real induction arrows around the southern part of the Indian peninsula.

the outburst of Reunion Plume. As noted earlier, the region is also marked by LVZ and LMA and also remains a place of high heat flow. Interestingly, here also, like the southern peninsula, the induction arrows have very large magnitudes, suggesting structure with high conductance. Thin sheet modeling has estimated a conductance of the order of $15000 \mathrm{~S}$ for the SIOCA. Recently, Simpson et al. (2000) have shown that the currently active Hawaiian Plume head with an average melt fraction of $4-6.6 \%$ distributed throughout the $55 \mathrm{~km}$ thick region having a temperature of $1460^{\circ} \mathrm{C}$ could have conductance of the order of 25000-40000 S. Although the Marion Plume outburst took place approximately $85 \mathrm{Ma}$, the region affected by the outburst traversed again over the Reunion hotspot. This later thermal remobilization/reactivation around 40-50 Ma might have prolonged the decay period of the plume associated thermal anomaly that otherwise decays to insignificance in a period of 60 $70 \mathrm{Ma}$. It also seems possible to visualize that this thermal reactivation may trigger release of hydrous fluids/volatiles that could be an additional source for the enhanced conductivity of the medium. Further, the propagation of the thermomagmatic fluxes related to the Marion Plume uprising or that indicted by the movement over the Reunion hotspot could be guided by the already existing rifted margin along the east coast (Raval and Veeraswamy; 2000) and, thus, could have focused thermal remobilization along such structures.
In the reconstructed Gondwanaland, Lawver and Scotese (1987) and Storey (1995) have shown that Indian Ocean hotspots (Crozet, Marion and Kerguelen), just prior the break-up the Gondwanaland were located beneath the thick east Antarctica Craton. But in the early phase of the breakup of Gondwanaland, i.e. immediately after the separation of India, Antarctica and Australia, the Marion Plume passed between India and Sri Lanka. The evidence of pre-outburst volcanism in deep wells in the Gulf of Mannar tends to support such conjecture. Thermally altered crust along the east coast of India, either in association with pre-outburst or outburst of the Marion Plume may be the source for the enhanced conductivity mapped along the Palk-Strait.

In conclusion, the integrated modeling of the EM response functions from the peninsular India and the Bay of Bengal have placed more severe constraints on the location and sources of the high conductivity zones. The incorporation of the signatures of allied geophysical anomalies have helped to visualize a tectonic evolution model that permit to relate the SIOCA and conductivity anomaly beneath the Palk-Strait to the thermal interaction of the Marion Plume with the Indian Lithosphere. However, it may be noted that locations of both SIOCA and Palk-Strait conductor are mapped by measurements made only from one side of the structures. New seafloor EM measurements around the southern tip of India will fulfill long term need to map 
the electrical conductivity structures in more detail.

Acknowledgments. Workshop on Plume Tectonics, jointly organized by National Geophysical Research Institute, Hyderabad and Department of Science and Technology, Government of India, during June 13-14, 2000 at Hyderabad provided stimuli to undertake the work presented in this paper. The authors wish to thank the principal organizer U. Raval for his prompting and many useful discussions. The authors thank B. L. N. Kennet for supplying and permitting to reproduce the Fig. 6(a). H. Toh and M. Ingham are thanked for their constructive comments on the earlier version of the manuscript. The authors also wish to thank their colleagues who willingly participated in the field campaigns to collect the data that paved the way for the present work.

\section{References}

Agarwal, A. K. and J. T. Weaver, Regional electromagnetic induction around the Indian peninsula and Sri-Lanka; a three-dimensional numerical model study using the thin sheet approximation, Phys. Earth Planet. Inter, 54, 320-331, 1989.

Arora, B. R., Magnetometer array studies in India: present status, data interpretation and assessment of numerical modeling results, Proc. Indian. Acad. Sci., 99, 693-716, 1990.

Arora, B. R. and C. D. Reddy, Magnetovariational study over a seismically active area in the Deccan trap province of western India, Phys. Earth Planet. Inter., 66, 118-131, 1991.

Arora, B. R., M. V. Mahashabde, and R. Kalra, Indian IEEY geomagnetic observational program and some preliminary results, Braz. J. Geophys., 11, 365-386, 1993.

Arora, B. R., G. Rawat, P. B. V. Rao, R. N. Maurya, and R. V. Iyengar, Long period magnetotelluric measurements in the Dharwar craton, South India, Joint IAGA \& IASPEI Assembly, Hanoi, August 19-31, 2001.

Basu, A. R., P. R. Renne, D. K. Dasgupta, F. Teichman, and R. J. Poreda, Early and late alkali igneous pulses and a high ${ }^{3} \mathrm{He}$ plume origin for Deccan flood basalts, Science, 261, 902-906, 1993.

Beamish, D., A geomagnetic precursor to the 1979 Carlisle earthquake, Geophys. J. R. astr. Soc., 68, 531-543, 1982.

Burke, K. C. A., L. Delano, J. F. Dewey, A. Edelstein, W. S. F. Kidd, K. D. Nelson, A. M. C. Sengor, and J. Strup, Rifts and structures of the world. Contract Rep. Nas 5-24094, Geophys. Branch, ESA Div., Goddard Space Flight Center, Greenbelt, Md., 238, 1978.

Curray, J. R. and T. Munasinghe, Origin of the Rajmahal Traps and the $85^{\circ} \mathrm{E}$ Ridge: Preliminary reconstructions of the trace of the Crozet hotspot, Geology, 19, 1237-1240, 1991.

Curray, J. R., F. J. Emmel, D. J. Moore, and R. W. Raitt, Structure, tectonics and geological history of the northeastern Indian ocean, in The Ocean Basin and Marigins, 6: The Indian Ocean, edited by A. E. M. Nairn and F. G. Stehli, pp. 399-450, Plenum Press, New York, 1982.

Drury, S. A., N. B. W. Harris, R. W. Holt, S. G. J. Reeves, and R. T, Wightman, Precambrain tectonics and crustal evolution in south India, J. Geol., 92, 3-20, 1984.

Duncan, R. A. and M. A. Richards, Hotspots, mantle plumes, flood basalts, and true Polar wander, Rev. Geophys., 29, 31-50, 1991.

Egbert, G. D. and J. R. Booker, Robust estimation of geomagnetic transfer functions, Geophys. J. R. Astr. Soc., 87, 173-194, 1986.

Fujiwara, S. and H. Toh, Geomagnetic Transfer Functions in Japan Obtained by First Order Geomagnetic Survey, J. Geomag. Geoelectr., 48, 1071-1101, 1996.

GSI, Geological Map compiled by A. K. Dasgupta, A. Ghose, and K. K. Chakraborty. Published by Geological Survey of India, Calcutta, India, 1993.

Heinson, G. S. and F. E. M. Lilley, An application of thin sheet electromagnetic modeling to the Taman sea, Phys. Earth Planet. Inter., 81, 231-251, 1993.

Honkura, Y., N. Watanabe, Y. Kaneko, and S. Oshima, Anisotropy in electromagnetic field variations and its implication for lateral inhomogeneity of the electrical conductivity structure, Phys. Earth Planet. Inter., 53, 278-286, 1989.

Joseph, E. J., R. V. Iyengar, L. A. D'Cruz, and B. P. Singh, Seafloor Geomagnetic Sounding near the $85^{\circ} \mathrm{E}$ Ridge in the Bay of Bengal, $J$. Geomag. Geoelectr., 47, 421-430, 1995.

Joseph, E. J., H. Toh, H. Fujimoto, R. V. Iyengar, B. P. Singh, H. Utada, and J. Segawa, Seafloor electromagnetic induction studies in the Bay of Bengal, Marine Geophysical Res., 21, 1-21, 2000.
Kennett, B. L. N. and S. Widiyantoro, A low seismic wavespeed anomaly beneath northwestern India: a seismic signature of the Deccan plume?, Earth Planet. Sci. Lett., 165, 145-155, 1999.

Lawver, L. A. and C. R. Scotese, A revised reconstruction of Gondwanaland, in Gondwana 6: Structure, Tectonics, and Geophysics, edited by G. D. McKenzie, pp. 17-23, Washington, D.C., American Geophysical Union Monograph, 40, 1987.

Mareschal, M., G. Vasseur, B. J. Srivastava, and R. N. Singh, Induction models of southern India and effect of offshore geology, Phys. Earth Planet. Inter., 45, 137-148, 1987.

Naqvi, S. M., V. Divakar Rao, and H. Narain, The proto-continental growth of Indian shield and the antiquity of its rift valleys, Precambrain Res., 1, 338-345, 1974.

Nityananda, N., A. K. Agarwal, and B. P. Singh, Induction at short period on the horizontal field variation in the peninsular India, Phys. Earth Planet. Inter, 15, 5-9, 1977.

Norton, I. O. and J. G. Sclater, A model for the evolution of the Indian ocean and breakup of Gondwanaland, J. Geophys. Res., 84, 6803-6830, 1979.

Peirce, J. W., The northward motion of India since the late cretaceous, Geophys. J. R. Astron. Soc., 52, 277-311, 1978.

Radhakrishna, B. P. and R. Vaidyanadhan, Geology of Karnataka, Geol. Soc. India., Bangalore, India, 1997.

Rajaram, M., B. P. Singh, N. Nityananda, and A. K. Agarwal, Effect of the presence of a conducting channel between India and Sri-Lanka on the features of the Equatorial Electrojet, Geophys. J. R. Astron. Soc., 56, 127-138, 1979.

Ramana, M. V., V. Subrahmanyam, A. K. Chaubey, T. Ramaprasad, K. V. L. N. S. Sarma, K. S. Krishna, M. Desa, and G. P. S. Murty, Structure and origin of the $85^{\circ}$ E Ridge, J. Geophys. Res., 102, 17995-18012, 1997.

Ramaswamy, V., A. K. Agarwal, and B. P. Singh, A three dimensional numerical model study of the electromagnetic induction around the Indian peninsula and Sri Lanka island, Phys. Earth Planet. Inter., 39, 52-61, 1985.

Ramkrishnan, M., Tectonic evolution of the granulite terrains of southern India, in Continental Crust of South India, edited by B. P. Radhakrishna, Mem. Geol. Soc. India, 25, pp. 45-61, 1993.

Raval, U. and K. Veeraswamy, The radial and linear modes of interaction between mantle plume and continental lithosphere: A case study from western India, J. Geol. Soc. India, 56, 525-536, 2000.

Richards, M. A, R. A. Duncan, and U. E. Courtillot, Flood basalts and hot spot tracks: Plume heads and tails, Science, 246, 103-107, 1989.

Royer, J. Y., J. W. Peirce, and J. K. Weissel, Tectonic constraints on the hotspot formation of Ninetyeast ridge, Proc. Ocean Drill. Program, Scientific results, 121, 763-776, 1991.

Schmucker, U., Anomalies of Geomagnetic variations in the southwest United States, Bull. Scripps Inst. Oceanog., 13, 165, 1970.

Simpson, F., E. Steveling, and M. Leven, The effect of the Hawaiian plume on the magnetic daily variation, Geophys. Res. Lett., 27, 1775-1778, 2000.

Singh, B. P., N. Nityananda, and A. K. Agarwal, Induced magnetic variation in the Indian Peninsula, Acta Geodact. Geophys. Montanist Acad. Sci. Hung., 12, 65-72, 1977.

Singh, B. P., A. K. Agarwal, and L. Carlo, Anomalies in H at Indian equatorial stations and their effect on equatorial enhancements, J. Atmos. Terr. Phys., 44, 241-244, 1982.

Singh, B. P., Mita Rajaram, and V. J. Bapat, Definition of the continentocean boundary of India and the surrounding oceanic regions from Magsat data, Tectonophys., 192, 145-151, 1991.

Storey, B. C., The role of mantle plumes in continental breakup: case histories from Gondwanaland, Nature, 377, 301-308, 1995.

Subba Rao, P. B. V., B. P. Singh, and P. B. Gawali, A geoelectrical section across the Andaman Arc Sea, Northeast Indian by using Ocean Bottom Magnetometers, J. Geol. Soc. India, 55, 47-64, 2000.

Subrahmanyam, C., N. K. Thakur, T. Gangadhara Rao, R. Khanna, M. V. Ramanna, and V. Subrahmanyam, Tectonics of Bay of Bengal: new insights from satellite-gravity and ship-borne geophysical data, Earth and Planetary Sci. Lett., 171, 237-251, 1999.

Thakur, N. K., M. V. Mahashabde, B. R. Arora, B. P. Singh, B. J. Srivastava, and S. N. Prasad, Geomagnetic variation anomalies in peninsular India, Geophys. J. R. Astron. Soc., 86, 839-854, 1986.

Vasseur, G. and P. Weidelt, Bimodel electromagnetic induction in nonuniform thin sheets with an application to the northern Pyrenean induction anomaly, Geophys. J. R. Astron. Soc., 51, 669-690, 1977.

Wang, L. J., F. E. M. Lilley, and F. H. Chamalaun, Large-scale electrical 
conductivity structure of Australia from the magnetometer arrays, Exploration Geophysics, 28, 150-155, 1997.

Weaver, J. T., Regional induction in Scotland; and example of threedimensional numerical modeling using the thin sheet approximation, Phys. Earth Planet. Inter, 28, 161-180, 1982.

Weis, D., F. A. Frey, A. Saunders, I. Gibson, and leg 121 scientific ship- board party, Ninetyeast Ridge: A $5000 \mathrm{~km}$ record of a duple mantle plume, Geology, 19, 99-102, 1991.

B. R. Arora (e-mail: bra@iig.iigm.res.in) and P. B. V. Subba Rao 